\title{
O uso de jogos e simulação computacional como instrumento de aprendiza- gem: campeonato de aviões de papel e o ensino de Hidrodinâmica ${ }^{+*}$
}

\author{
Ericarla de Jesus Souza ${ }^{1}$ \\ Doutoranda do Departamento de Física da Universidade Federal da Bahia \\ Salvador - BA \\ Luiz Adolfo de Mello ${ }^{2}$ \\ Departamento de Física - Universidade Federal de Sergipe \\ São Cristóvão - SE
}

\section{Resumo}

Este artigo apresenta uma pesquisa no ensino de Física utilizando como técnica de ensino-aprendizagem uma sequência didática construída a partir de jogos educacionais, atividades experimentais e simulações computacionais. O conteúdo abordado é o de hidrodinâmica e sua aplicação nos conceitos físicos envolvidos no voo de aviões. Reforçava-se o aprendizado do conteúdo através do uso de simulação computacional usando o software Modellus. A avaliação dos alunos foi feita com o uso de jogos didáticos: cruzadinhas, caça palavras e jogos dos sete erros. Realizou-se a avaliação do projeto através da aplicação de questões que avaliavam as concepções alternativas dos estudantes. $O$ referencial teórico baseia-se na teoria dos Modelos Mentais de Johnson-Laird e na teoria da aprendizagem significativa de Ausubel, de modo que as avaliações dos conhecimentos prévios dos alunos eram realizadas através de questionário avaliativo do tipo teste.

Palavras-chave: Ensino de Física; Formação de professores; Técnicas de ensino; Experimentação; Jogos no ensino.

\footnotetext{
+ The use of games and computer simulation as a learning tool: paper airplanes championship and Hydrodynamic teaching

* Recebido: dezembro de 2016.

Aceito: maio de 2017.

${ }^{1}$ E-mail: ericarla-matos@hotmail.com

2 E-mail: 1admello@uol.com.br
} 


\begin{abstract}
This article presents a Physics teaching research using as teachinglearning technique a didactic sequence constructed from educational games, experimental activities and computational simulations. The content covered in this work is hydrodynamics and its application in the physical concepts involved in airplane flight. Learning content is reinforced through the use of computer simulation using the software Modellus. The students' evaluation was made with the use of educational games: crosswords, word searches and games of the seven errors. The assessment was carried out through the application of questions that evaluated the students' alternative conceptions. The theoretical framework is based on the theory of mental models of John-Laird and in the theory of meaningful learning of Ausubel. So, the evaluations of previous knowledge of the students were made through evaluation of test type questionnaire.
\end{abstract}

Keywords: Physical Education; Teacher Training; Teaching Techniques; Experimentation.

\title{
I. Introdução
}

Dado o peso significativo que a experiência escolar (fundamental e média) tem para incentivar os estudantes à vocação científica vários países estão repensando e criando programas que incentivem uma forma melhor de se ensinar e formar profissionais do ensino. Hoje é consenso nos meios universitários e governamentais que o ensino de física no nível médio não pode ser descontextualizado do momento histórico em que ocorreu e de sua importância sócio econômico atual (PNLEM, 2015; PNLD, 2015; agência CYTA, OEI, 2015). Assim, fica a pergunta: como realizar a tarefa de ensinar física de forma mais conceitual e experimental, com menos enfoque em teorias e formulações matemáticas, e ao mesmo tempo realizar a conexão entre esta disciplina com a história do desenvolvimento científico de nossa sociedade?

Desde a introdução dos grandes projetos de ensino de Física, como o Physical Science Study Committee (PSSC, 2015), The Project Physics Course (Holton, 2003), o Projeto de Ensino de Física (PEF, 1980), as atividades experimentais são consideradas como ferramentas indispensáveis no ensino de física. As aulas de Física, em algumas escolas, estão se tornando mais lúdicas e interativas, estimulando os estudantes a terem uma atitude mais ativa diante do processo de ensino-aprendizagem.

Grosso modo, os projetos de ensino de física revolucionaram a educação mundial ao criar e colocar em prática a ideia que a produção de material pedagógico de bom nível, tais como livros textos, textos paradidáticos, kits de experiências e vídeos aulas, acompanhado pelo 
devido treinamento dos professores engajados no projeto, conseguiria atrair mais estudantes para a carreira científica, mais especificamente para as ciências exatas.

Contudo, a mera produção de material didático não produziu os resultados esperados. Com a aplicação destas novas tecnologias educacionais (na época) observou-se que houve uma melhora significativa no aprendizado de ciências em geral, mas algumas lacunas ficaram para serem resolvidas. Dentre os vários problemas detectados constatou-se que os estudantes raciocinavam usando concepções prévias ou alternativas em vez de concepções científicas (CAREY, 1987; PEDUZZI, 1992; VILLANI, 1997), que estes usam modelos mentais em vez de modelos científicos (JOHNSON-LAIRD, 1997; MOREIRA, 1999; HARRISON, 2007; HALLOUN, 1996), e a grande maioria dos estudantes não enxergam a relação entre a ciência ensinada em sala de aula e o cotidiano (PNLD, 2015).

Cabe notar que Mendes (1999) obteve resultados inconclusos em pesquisa anterior utilizando uma sequência didática construída utilizando somente o Software Modellus e o experimento de baixo custo "lançamento de foguete". A turma que teve melhor desempenho foi justamente o grupo controle. Ficamos muito intrigados com este fato e passamos a discutir as razões desse insucesso já que tínhamos bons retornos, mas qualitativos, usando sequencias didáticas utilizando o Software Modellus.

Apresentamos abaixo uma proposta pedagógica para o ensino de ciências em geral que tenta atacar ou resolver estas lacunas, sem ter que lançar mãos das intermináveis revisões ou aplicações de testes. Nessa proposta "as revisões" são feitas pela própria seqüência didática em que a teoria é ilustrada com aplicações do conteúdo de hidrodinâmica à Física do voo do avião, complementada com atividades experimentais, simulações computacionais e jogos educacionais. A avaliação do ensino é realizada através da aplicação de pré e pós-teste com questões tipo concepções alternativas (SADLER, 1992; ARNAUDIN, 1985; BELL, 1987) e através de jogos educacionais.

Esse projeto está inspirado na política educacional do MEC denominado PIBID (Programa Institucional de Bolsas de Iniciação à Docência) (PIBID, 2015). Alguns dos objetivos propostos por este projeto e tirado do PIBID são:

- incentivar a formação de professores para a educação básica, especialmente para o ensino médio;

- promover a melhoria da qualidade da educação básica;

- fomentar experiências metodológicas e práticas docentes de caráter inovador, que utilizem recursos de tecnologia da informação e da comunicação, e que se orientem para a superação de problemas identificados no processo ensino-aprendizagem;

- valorizar o espaço da escola pública como campo de experiência para a construção do conhecimento na formação de professores para a educação básica;

- proporcionar aos futuros professores participação em ações, experiências metodológicas e práticas docentes inovadoras, articuladas com a realidade local da escola. 


\section{Referenciais teóricos}

Tendo em vista essas metas reunimos algumas práticas pedagógicas e experiências institucionais de modo a criar um modelo de sequência didática factível para ser aplicada em sala de aula. Esta é composta pela realização de oficinas experimentais com materiais de baixo custo juntamente com a realização de atividades lúdicas com jogos educacionais e a utilização de simulações através de um software desenvolvido para o ensino de Física denominado $\mathrm{Mo}$ dellus (TEODORE, 2002). A meta deste projeto é fazer com que os alunos do segundo ano do Ensino Médio compreendam os conceitos de Hidrodinâmica e os conceitos físicos aplicados em um voo de avião, como também despertar o gosto pela Física.

Escolheu-se o conteúdo de Hidrodinâmica primeiramente pelo fato deste estar presente no nosso dia a dia e possuir diversas aplicações tecnológicas. Em segundo lugar, nos deparamos com vários materiais de divulgação sobre o tema (MENDES, 2009; STUDART, 2012; PEREIRA, 2012) indicando o interesse geral sobre o tema, apesar da Física do voo de avião não ser abordado no curso regular do ensino médio. Pelo fato da maioria das escolas não abordarem esse conteúdo, optamos por fazer uso de jogos e simulação, tanto como motivação e como técnica de avaliação da sequência didática.

Essa pesquisa foi realizada com alunos do $2^{\circ}$ ano do ensino médio do Centro de Excelência Ministro Marco Maciel (C.E.M.M.M) da cidade de Aracaju - SE, e com estudantes do Colégio de Aplicação (CODAP) da Universidade Federal de Sergipe. Nessa pesquisa não se utilizou turma de controle, de modo que aplicamos e avaliamos essa sequência didática em todas as turmas dessas escolas. A avaliação dos alunos e do projeto foi realizada através do desempenho comparativo dos estudantes usando questões que avaliem concepções alternativas e do tipo vestibular (tiradas de livros didáticos).

\section{Aprendizagem Significativa}

Como dito acima, a mera utilização das TICS e de atividades experimentais em sala de aula não resolvem todos os problemas do ensino. Observou-se que os estudantes não eram capazes de explicar novos fatos experimentais correlacionados com o conteúdo previamente aprendido (VILLANI, 1997; CLEMENT, 1982). Para que haja uma efetiva aprendizagem dos conteúdos de física estes devem poder articular e interpretar novos fatos científicos com os conceitos aprendidos. Em linguagem da psicologia da aprendizagem diz-se que não há aprendizagem significativa.

Resumidamente, Ausubel (1989) elaborou a teoria da aprendizagem significativa em contraposição à aprendizagem mecânica ou bancária (FREIRE, 2005), como um processo onde uma nova informação interage com algum aspecto relevante da estrutura do conhecimento do indivíduo. Essa aprendizagem dá-se quando há interação de uma nova informação a um aspecto relevante da estrutura cognitiva do aluno (MOREIRA, 1999).

Mas essa aprendizagem não é uma mera associação de ideias. Ausubel (2000) propõe duas condições básicas para que ocorra a aprendizagem significativa: 
As informações a serem assimiladas devem ser potencialmente significativas para o aprendiz, ou seja, ele tem de ter em sua estrutura conceitos relacionáveis, de forma substantiva e não arbitrária vinculada diretamente com o conhecimento a ser aprendido, o qual, por sua vez, deve ter significado lógico.

O aprendiz deve manifestar uma disposição para relacionar o novo material, de forma significativa e não arbitrária, à sua estrutura cognitiva. Ou seja, mesmo que tenhamos uma informação significativa e o aluno não quiser aprender, está aprendizagem poderá ser mecânica e ou nem ocorrer.

Segundo essas premissas, os estudantes deveriam possuir: 1) em sua estrutura cognitiva (no caso de ciências) conceitos físicos relacionáveis com o conteúdo a ser aprendido e 2) interesse pelo assunto. Mas, o que fazer quando na estrutura cognitiva do aprendiz prevalecem as concepções alternativas? O que se confirma aqui é que o professor deve considerar os conhecimentos não científicos (empíricos ou espontâneos) trazidos pelos alunos e ajudá-los a partir desse ponto a transformar esses conhecimentos em conceitos científicos. Para isso utilizamos de recursos tecnológicos, experimentais ou de jogos como forma de torná-lo atrativo e obter a dinamização do ensino-aprendizado. Assim, cria-se uma ponte entre sala de aula - teorias Físicas - e a realidade vivenciada pelos alunos. Deste modo o conteúdo é apreendido de forma significativa, pois está relacionado a outras ideias e conceitos e estas funcionam como âncora, de modo que o conteúdo fica claro na mente do aluno.

\section{Modelos Mentais}

Desde o início das pesquisas em Inteligência artificial (IA) constatou-se que os seres humanos raciocinam através de modelos (GALAGOVSKY, 2001; GILBERT, 1993; GRECA, 2002; MOREIRA, 1996). Logo, alguns pesquisadores se debruçaram sobre a problemática de se determinar que tipos de modelos os homens usam em sua vida diária (MOREIRA, 1996; NESSERSSIAN, 1992; JOHNSON-LAIRD, 1997). Constatou-se que esses modelos podem ser de diversas naturezas. Aqui só abordaremos as ideias de Johnson-Laird sobre o tema.

Johnson-Laird (1983, p 163) defende que as pessoas raciocinam através de modelos mentais. Modelos mentais, analogicamente a modelos da arquitetura, são como blocos de construção cognitivos que podem ser combinados e recombinados conforme necessário. Como quaisquer outros modelos eles representam acuradamente ou não o objeto ou situação em si. Uma de suas características mais importantes é que sua estrutura capta a essência (se parece analogicamente) com essa situação ou objeto (HAMPSON; MORRIS, 1996, p. 243).

Assim, outro fator a ser considerado nas dificuldades associadas ao ensino e aprendizagem de Física está nos aspectos abstratos dessa disciplina. Por sua natureza as teorias físicas são construídas a partir da construção de modelos matemáticos, hipóteses e teoremas confrontados com fatos experimentais. Os exemplos clássicos são os modelos atômicos, o uso e abuso da aproximação do oscilador harmônico e outros. Assim, é consenso entre um grupo de pesquisadores na área denominada "teoria cognitiva da Ciência" que para explicar os sistemas físicos 
os físicos constroem modelos conceituais da natureza. Por outro lado, como afirma JohnsonLaird (1983, p. 163), os alunos também constroem seus modelos do universo ao seu redor. (Ver NESERSSIAN, 1992; IZQUIERDO, 1999; KOPONEN, 2007; MOREIRA, 1996; GALAGOVSKY, 2001; e outros).

Mas há uma diferença básica: os modelos físicos são modelos conceituais, isto é, modelos construídos por pesquisadores para poderem elaborar suas teorias e que acabam por facilitar a compreensão ou o ensino de sistemas físicos. São representações precisas, consistentes e completas de fenômenos físicos segundo determinada teoria (MOREIRA, 2002). Porém, os modelos dos alunos, ou de qualquer indivíduo, inclusive os que criam modelos conceituais, são modelos mentais, ou seja, modelos que as pessoas constroem para representar estados de coisas físicas (bem como estados de coisas abstratas) (JOHNSON-LAIRD,1983; MOREIRA, 1996; GRECA, 2002).

\section{Concepções alternativas}

Dizendo em uma linguagem mais simples o que foi dito acima, as interpretações e explicações dadas pelas pessoas a diferentes fenômenos físicos dependem do tipo de instrução ou educação que essa teve durante sua vida e de sua pré-disposição em refletir sobre os fenômenos naturais observados. Isto é, isso significa que nem toda interpretação que um indivíduo use para explicar uma situação e/ou fenômeno físico tenha sua origem na escola.

Até a década de 70, as pesquisas em ensino de ciências eram norteadas pelos trabalhos de Piaget e colaboradores. Essas pesquisas davam excessiva importância ao desenvolvimento de estruturas lógicas subjacentes ou "esquemas" de Piaget (DRIVER; EASLEY; 1978). A partir dessa década começou a aparecer na literatura um grande número de estudos preocupados, especificamente, com os conteúdos das ideias dos estudantes em relação aos diversos conceitos científicos aprendidos na escola (SADLER, 1992; BELL, 1985; ARNAUDIN, 1987; MORTINER, 1996).

Na década de 80 surgiram várias críticas à ideia simplista que a teoria de esquemas de Piaget poderia explicar ou resolver todos os problemas do ensino de ciências (AUSUBEL; NOVAK; HANESIAN, 1980; NOVAK, 1981; entre outros). Gilbert e Swift (1985) denominaram o movimento dos pensadores preocupados com os conteúdos das ideias dos estudantes de "movimento das concepções alternativas". Na década de 80 e 90 houve interesse acentuado na investigação no campo das concepções alternativas dos estudantes, que redundou em profundo conhecimento de seu papel no ensino de ciências em geral. Para maiores detalhes, ver Leite (1993) e Salem (2012).

De um modo geral, estes estudos utilizam métodos qualitativos para tentar compreender os conceitos que os estudantes trazem consigo (tal como ele entra em sala aula), para posteriormente definir o processo de ensino e aprendizagem pela qual o estudante passará pela transição entre o estado "de concepções prévias para as científicas". Isto é, o de domínio ou 
entendimento das explicações científicas, ou compreensão dos conceitos científicos (MESTRE; TOUGER, 1989).

A partir dessa teoria chegamos à conclusão que a mente do estudante não é, em linguagem moderna, um DVD virgem onde o professor possa gravar a informação que desejar. A sua interação com o mundo que o cerca o habilita a criar esquemas explicativos (na linguagem de Piaget) ou modelos mentais (na linguagem de Jhonson-Laird), que lhe permite fazer previsões e mesmo "explicar" diversos fenômenos físicos do seu cotidiano. Segundo Peduzzi (1992, p. 240) estas construções, na forma de concepções, conceitos ou ideais intuitivas, alternativas:

a) São encontradas em um grande número de estudantes, em qualquer nível de escolaridade;

b) Constituem um esquema conceitual coerente, com amplo poder explicativo;

c) Diferem das ideias expressas através dos conceitos, leis e teorias que os alunos têm que aprender;

d) São muito persistentes e resistem ao ensino de conceitos que conflitam com elas;

e) Não se debilitam, mesmo frente a evidências experimentais que as contrariam;

f) Interferem no aprendizado da Física, sendo responsáveis, em parte, pelas dificuldades que os alunos enfrentam em disciplinas desta matéria.

g) Apresentam semelhanças com esquemas de pensamento historicamente superados.

Apesar do reduzido número de trabalhos publicados nos últimos anos no campo de pesquisa sobre concepções alternativas (SALEM, 2012), os seus resultados e conclusões continuam sendo válidos e sendo aplicados. Seguindo a filosofia dos mentores dessa teoria utilizamos um questionário contendo questões avaliativas de concepções prévias, de modo a nortear a elaboração de um material didático que levasse em conta a existência dessas concepções e que introduzisse as concepções científicas de modo a gerar conflitos cognitivos com as primeiras. Como mostrar-se-á aqui, isto gerou condições pedagógicas para se produzir uma aprendizagem significativa nos instruendos.

\section{Experimentação e simulações computacionais no Ensino de Física}

O que fazer ou como gerar uma aprendizagem significativa quando as concepções dos estudantes não são as científicas, mas sim as prévias. Uma das formas mais eficientes é a da utilização de atividades experimentais e/ou simulações computacionais.

Como tem sido enfatizada por muitos autores, o uso da experimentação e de simulações computacionais no ensino de Física é de fundamental importância no processo ensinoaprendizagem (ARAUJO, 2012; ALVES, 2012; VEIT, 2002 E 2005; SOUZA, 2013; TEODORO, 2002). Como mostramos acima, contribuições importantes da teoria da aprendizagem na elucidação de que forma se processa a construção do conhecimento apontam para a necessidade de um ensino experimental e com modelagens complementando o ensino tradicional.

Atividades experimentais (ZANON, 2008), e modelagens (ANDALORO, 1991; KOPONEN, 2007) podem assumir papel fundamental na promoção de aprendizagens significativas 
em ciências e, por isso, cada vez mais se tem dado importância à valorização de propostas alternativas de ensino que demonstrem potencialidade da experimentação através de inter-relações entre os saberes teóricos e práticos inerentes aos processos do conhecimento escolar.

Segundo os teóricos citados acima e nas palavras de Araujo e Abid (2012),

\begin{abstract}
A experimentação e as modelagens computacionais tem papel fundamental no processo de construção conceitual, visto que muitas vezes é necessário "desconstruir" conceitos desenvolvidos pelo senso comum, de modo que, é imprescindível que o educando visualize a situação, observe e analise os resultados para perceber e mudar o seu pensamento, não apenas acatar o que o professor diz.
\end{abstract}

Neste aspecto é imprescindível que o estudo de um conceito inicie com uma atividade experimental e/ou simulação, visto que, muitas vezes, seus modelos mentais são inconsistentes e/ou conflitantes com os modelos científicos.

A experiência mostrou que modelos simplificam objetos e processos complexos (Kinnear, 1992), e modelos exagerados melhoram a aprendizagem (OGBORN, 1996). Mas, os modelos não são tão eficazes para explicar conceitos científicos como supomos. Em geral, os alunos acham difícil gerar os seus próprios modelos como entender os modelos fornecido pelos professores (ZOOK, 1991). Alguns pesquisadores abordaram recentemente essa questão (GILBERT, 1991; HALLOUN, 1996; WELLS, 1995) mas, não há ainda uma teoria finalizada sobre a forma como os professores ensinam e os alunos aprendem por meio de modelos. Glynn (1991) e Duit (1991) insistem que os professores devem ajudar seus alunos a identificar os atributos compartilhados e não compartilhados de todos os modelos e analogias (HARRISON, 2001).

Assim, se conclui da necessidade de se produzir sequências didáticas que envolvam atividades experimentais, jogos e simulações, já que como afirmam alguns autores (GUIMARÃES, 2009):

Ao ensinar ciência no âmbito escolar deve-se também levar em consideração que toda observação não é feita num vazio conceitual, mas a partir de um corpo teórico que orienta a observação. Logo, é necessário nortear o que os estudantes observarão.

\title{
O uso dos jogos como instrumento de avaliação
}

A avaliação ainda é um objeto de pesquisa com muitos enfoques, como sociológico, filosófico e até político. Diversos autores (RICHARDSON, 1979; SILVA, 2012) afirmam que a avaliação não é um mero apêndice do conteúdo ministrado. Como na metodologia construtivista a avaliação é uma peça chave do processo de ensino-aprendizagem, e no nosso caso é peça fundamental da elaboração da sequência didática.

Observa-se que as práticas avaliativas da maioria das escolas brasileiras se resumem a exames sistematizados, que giram em torno de questões mecânicas, onde uma grande parte dos alunos memorizam conteúdos e fórmulas para fazer uma prova e no dia seguinte esquecem tudo 
o que foi estudado (RODRIGUES, 2015). O ambiente escolar em que este projeto foi inserido se caracteriza pela preparação dos estudantes a uma prova classificatória nacional denominada ENEM (2015).

Segundo Lakatos (2000) e Luckesi (2002), a avaliação da aprendizagem não é e não pode continuar sendo a tirana da prática educativa, que ameaça e submete os estudantes. Em geral se confundi avaliação da aprendizagem com exames. A avaliação da aprendizagem, por ser avaliação, é amorosa, inclusiva, dinâmica e construtiva, de caráter muito diverso dos exames, que não são amorosos, são excludentes, não são construtivos, mas classificatórios. A avaliação inclui, traz para dentro; os exames selecionam, excluem e marginalizam.

Através dos trabalhos de Cavalcanti e Soares (2009), Silveira (2008), Silva e Amaral (2011), reformulamos nossa maneira de avaliar e passamos a utilizar jogos como instrumento avaliativo dos alunos. Deste modo desenvolvemos jogos como cruzadinha, palavras cruzadas e jogo de sete erros para avaliar a aprendizagem escolar dos discentes durante o desenvolvimento das aulas e na sua finalização.

\section{Sequência didática}

Assim, desenvolveu-se nesse projeto um Produto Educacional com o objetivo de se buscar uma maior relação entre teoria, atividades lúdicas e as TICs, de modo que, se produzisse uma aprendizagem significativa a partir de uma sequência didática para o conteúdo de Hidrodinâmica.

Com esse material instrucional procura-se explicar e discutir os conceitos de Hidrodinâmica tendo como motivação suas aplicações nos voos de aeronaves. A sequência didática que descreveremos adiante utiliza uma pré-avaliação das concepções prévias e espontâneas dos conteúdos que serão abordados, simulação computacional no software Modellus para simular um voo de avião ou aeroplano, atividades lúdicas como campeonatos de avião de papel e o uso de jogos didáticos como método de avaliação.

\section{Oficina de aviões de papel}

Como o intuito de problematizarmos o tema a "Física do voo do avião" introduzimos uma oficina de construção de avião papel, que teve como objetivo ensinar e/ou auxiliar aos alunos na confecção de quatro modelos diferentes de aviãozinho de papel. Estes modelos são os mais tradicionais e apresentam maior desempenho em tempo de voo e/ou maior alcance. Para isso utilizamos alguns vídeos encontrados no youtube onde, apresentam um tutorial passo a passo para sua confecção. Após a confecção de cada modelo, os alunos faziam lançamento na sala de aula e podiam perceber as propriedades aerodinâmicas dos aviõezinhos e as diferentes maneiras de lançar cada modelo. A partir desta atividade o professor os questionava da razão do voo de alguns modelos terem maior alcance, em quantos outros terem maior tempo de permanência no ar. 
Em cada escola demos um prazo de duas semanas para que os alunos treinassem em casa o lançamento dos aviões e utilizassem a teoria e técnica estudada nas simulações no $\mathrm{Mo}$ dellus. Na semana seguinte, desta atividade no CODAP, realizamos um Campeonato de avião de papel na Universidade Federal de Sergipe, onde os seis selecionados de cada escola nas modalidades maior tempo de queda e maior alcance competiram entre si, disputando medalhas de ouro, prata e bronze.

Durante essa oficina procurou-se investigar as concepções prévias que os alunos traziam e ao mesmo tempo apresentar novos conceitos e explicações de fatores que influenciam no voo de um avião de papel, como também, a melhor forma de fazer lançamentos para se atingir um maior alcance e um maior tempo de permanência no ar.

\section{Material apostilado (Hidrodinâmica)}

Atualmente a grande maioria dos livros didáticos produzidos no Brasil para o Ensino Médio não apresenta o conteúdo de Hidrodinâmica e quando este conteúdo é abordado ou faz parte do último capítulo ou aparece em forma de Anexo 1. Assim, decidimos produzir um material de apoio em forma de apostila, permeado com atividades experimentais. Esse texto de apoio foi elaborado no "espírito" do GREF (2013). Ele foi escrito na forma de diálogo, onde o leitor é convidado a uma viagem de avião com duas paradas: a) a primeira parada é na REVISÃO: são revisados os principais conceitos e teorias da mecânica como velocidade, aceleração, leis de Newton entre outras. b) a segunda parada é na Aerodinâmica: nessa parte são aplicados alguns conceitos da Hidrodinâmica aplicadas ao voo de um avião. Esse material foi produzido de modo que os conceitos físicos eram sempre precedidos ou por algumas atividades experimentais ou por simulações. Como atividades experimentais temos:

\section{Atividade experimental I: corre-corre e anota}

Essa atividade tinha como objetivo que os alunos revisassem o conceito de velocidade média. Pedia-se a eles que se dividissem em grupo e registrassem o tempo gasto por um membro do grupo para percorrer um espaço fixo, do fundo da sala até quadro. Com o valor do tempo e espaço era pedido que os discentes calculassem a velocidade de cada um deles e construíssem uma tabela e um gráfico.

\section{Atividade experimental II: ação e reação}

Essa atividade tinha como objetivo verificar e revisar o princípio da ação e reação, utilizando uma bexiga, canudo e barbante. Foi pedido para que os alunos enchessem a bexiga com ar, e utilizando uma fita adesiva prendesse a bexiga a um canudinho. Logo em seguida, passasse um barbante pelo canudo e o mantivesse esticado. Depois, foi pedido para os alunos soltarem a bexiga e observasse o que acontecia com o balão. Na Fig. 1 podemos observar os alunos realizando essa atividade (CIENCIAMÃO, 2014). 


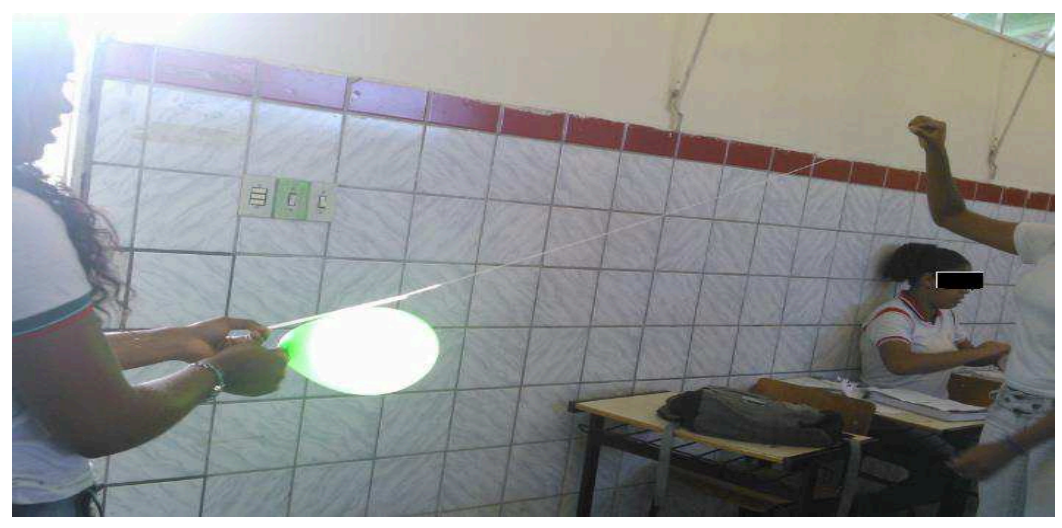

Fig. 1 - Verificando a terceira lei de Newton.

\section{Atividade experimental III: simulando uma asa de avião}

Para facilitar o entendimento de como o vento se comporta em uma asa de avião e confrontar a concepção prévia com a científica, foi construído com cartolina, canudo e barbante uma simulação de uma asa. Depois de confeccionado os alunos fizeram o teste diante do ventilador da sala de aula. Esticava-se o barbante com uma determinada inclinação, o vento fazia com que a asa se movimentasse para cima. Podemos observar o modelo da asa na Fig. 2 (CIÊNCIA BACANA, 2014).

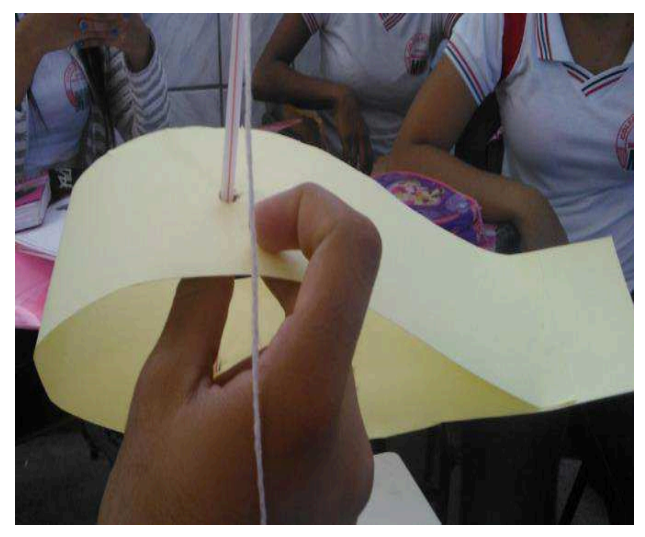

Fig. 2 - Simulação da asa de um avião.

\section{Atividade experimental IV: comprovando o efeito de Bernoulli}

Esta atividade foi organizada de modo a ilustrar e introduzir o Efeito Bernoulli. Nesta atividade foi construído um pequeno pulverizador. Foi utilizado um canudinho e feito um corte transversal, sem dividir o canudinho em duas partes. Dobrou-se o canudo e colocou-se a parte menor dentro de um copo com água e um pouco de tinta. Foi pedido que os alunos assoprassem pela extremidade, com isso, a água subiu pelo tubo e ao atingir o corte do canudo, se pulverizou e os alunos tentaram fazer desenhos como é mostrado na Fig. 3 (SAAD, 2014). 


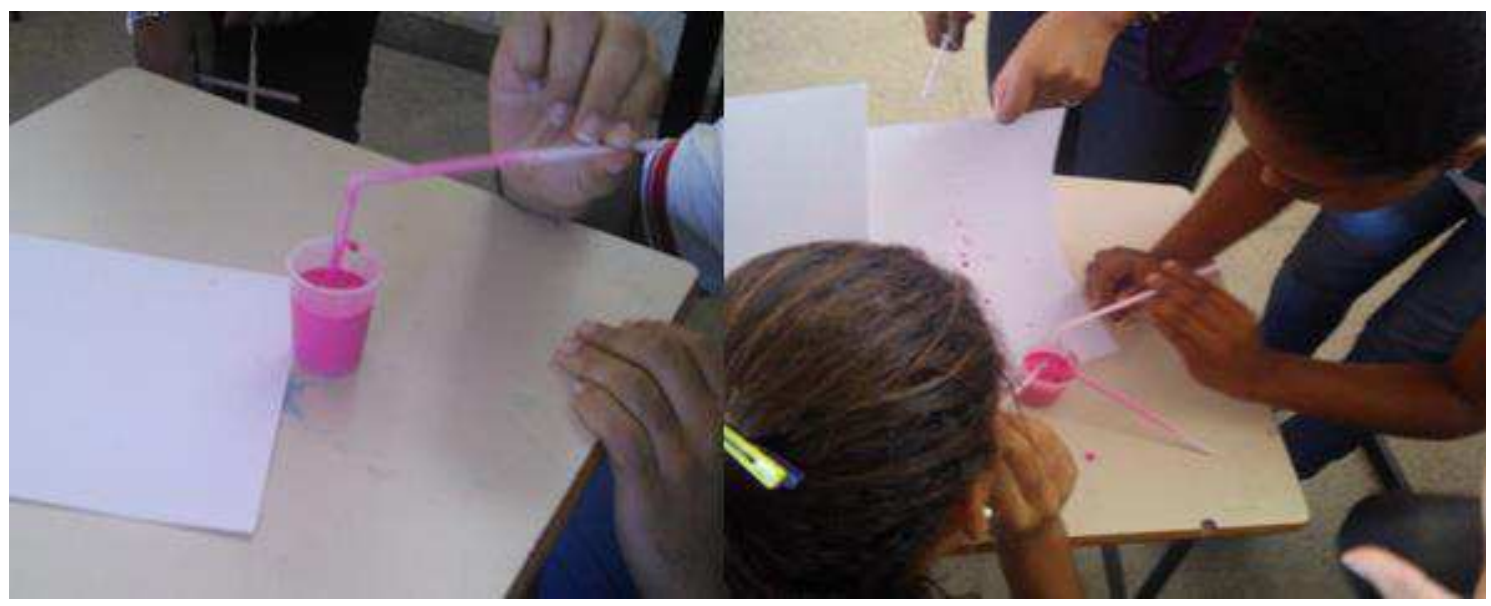

Fig. 3 -Construindo um pulverizador, comprovando o Efeito de Bernoulli.

\section{Simulação no Software Modellus}

Nessa atividade foram utilizadas duas simulações de voos, uma de um avião "normal" e outra de um aviãozinho de papel feito usando o software de ensino Modellus. A referência da modelagem matemática para essa simulação foi retirada da dissertação de J. F. Mendes (2009). Para a atividade de simulação do nosso trabalho tivemos que fazer algumas adaptações da modelagem matemática.

A modelagem matemática foi feita de modo que o parâmetro que modelava a dimensão horizontal das asas (Flap), das asas traseiras (Profundor) e o empuxo (Turbina) ficavam livres, ou seja, podiam ser alterados durante a simulação ao modo de um controle de simulador. Assim, os alunos podiam manusear os controles do "flap, profundor e turbina" do avião, fazendo com que o avião decolasse e controlasse seu voo em uma determinada altura. Já para a simulação do avião de papel, a turbina era desligada automaticamente depois de um determinado "tempo de lançamento" e era representada pela força exercida pelo garoto ao lançar o avião de papel como podemos observar na Fig. 4.

\section{Jogos avaliativos}

Como forma avaliativa utilizou-se jogos didáticos aplicados à Física. O primeiro jogo foi "Cruzadinha da Física".

A cruzadinha foi aplicada após a explanação de fatores históricos sobre a evolução do desejo de voar. Consistem em dez perguntas alternando entre perguntas na horizontal e na vertical. Este é um instrumento de coleta de dados na forma de um jogo, ajuda ao aluno fixar o conteúdo e desenvolver o raciocínio. Este jogo pode ser encontrado no Anexo 1. 


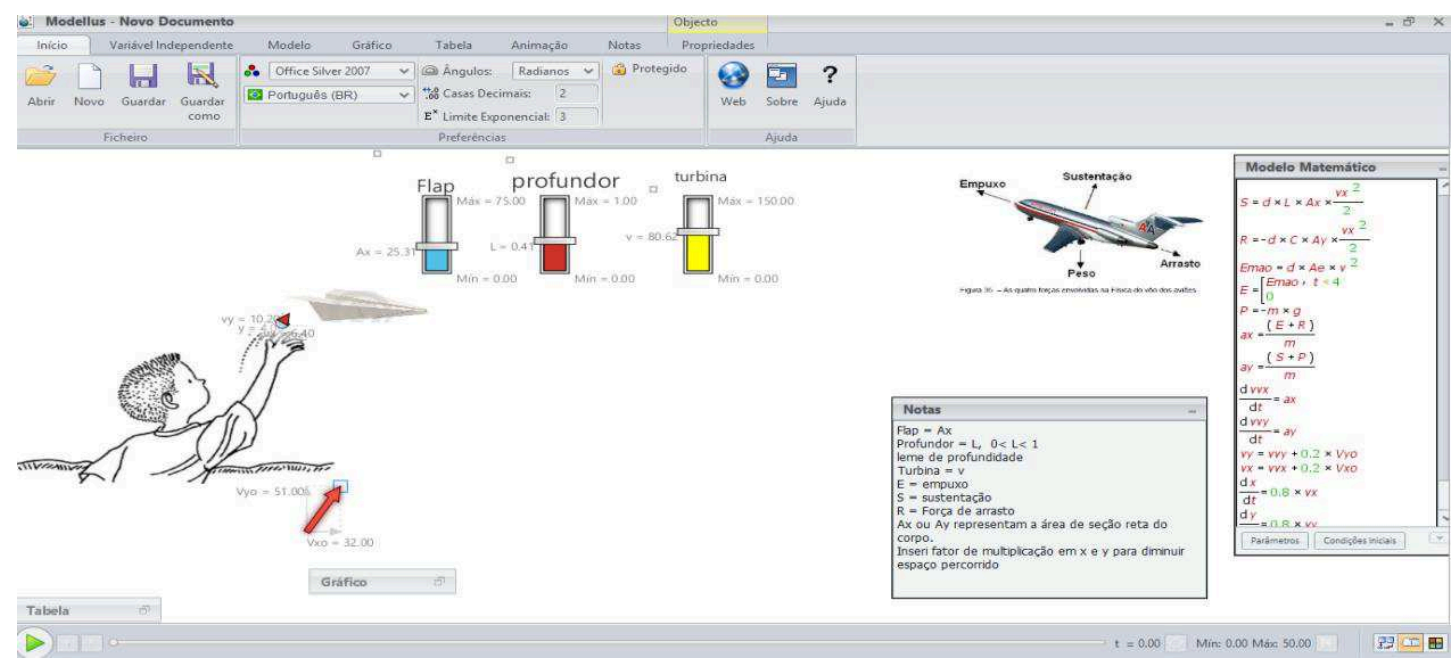

Fig. 4 - Visão da tela do simulador de voo de um avião de papel usando o software Modellus.

\section{Jogo dos Sete Erros e Caça Palavras}

Essa atividade lúdica foi elaborada para ser utilizada para se avaliar o interesse dos alunos e se aconteceu aprendizagem significativa após a aplicação da Sequência Didática e do Campeonato de Avião de Papel. Esse jogo é uma adaptação do jogo dos sete erros encontrado em almanaques e revistinhas em geral. Nesse jogo colocamos caixas de textos com identificadores em cada parte ou peça chave do avião. A ideia central é que a pessoa ou estudante deva distinguir na imagem do avião quais os identificadores estão colocados em posição errônea. Ver figura 5. Com o jogo caça palavras averiguamos se houve retenção do glossário do assunto abordado e com o jogo dos sete erros avaliamos se eles poderiam distinguir os principais componentes e conceitos de um avião. Ver Anexo 1.

\section{Exercício - Ache os sete erros.}

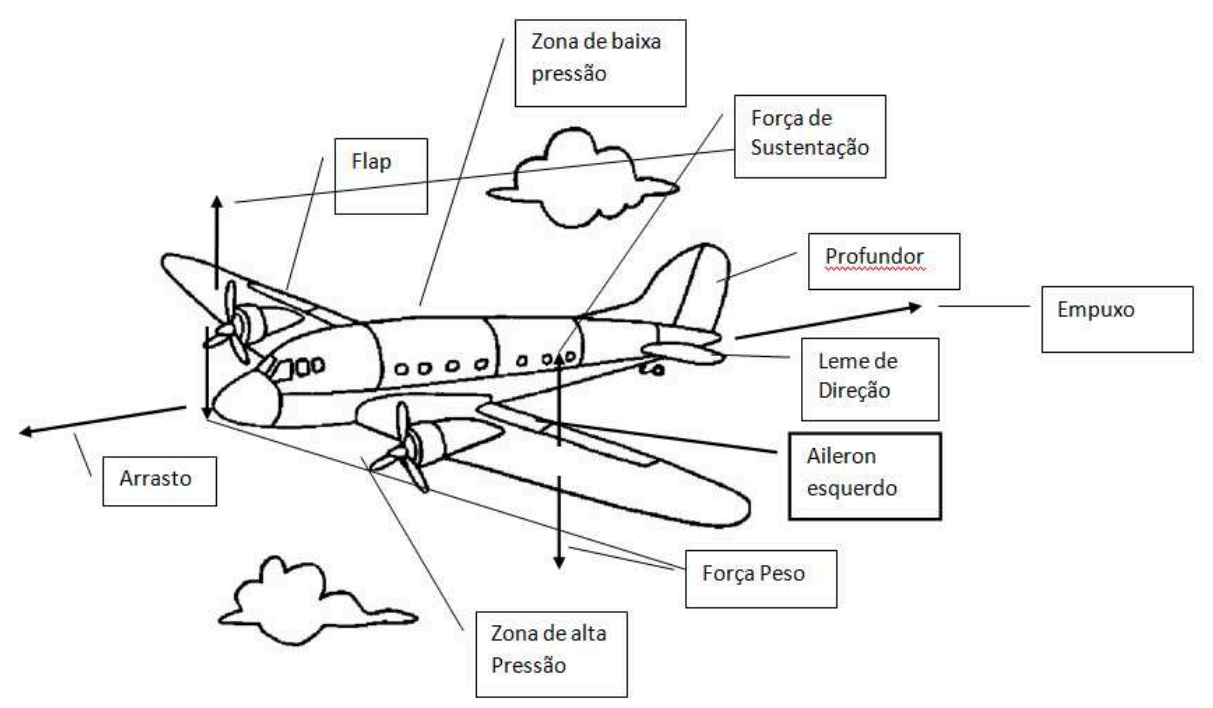

Fig. 5 - Jogo dos Sete Erros. 


\section{Metodologia}

Utilizamos para desenvolver esse trabalho a pesquisa-ação do tipo pesquisa Experimental (GIL, 1995) e adotamos abordagens metodológicas qualitativas e quantitativas. Ver LEITE (2008, p. 96). Diante disso, utilizamos ferramentas de coletas de dados nas quais conseguimos obter dados qualitativos e quantitativos. Logo, nosso referencial adotado no processo metodológico desta pesquisa está baseado segundo Eva Maria Lakatos (1990), Francisco leite (2008) e Richardson (1979) no enfoque quali-quantitativo.

$\mathrm{Na}$ análise qualitativa usamos como referenciais teóricos a teoria da aprendizagem significativa de Ausubel e a teoria das concepções prévias. Através da seleção de um conjunto de questões geradas com intuito de se medir ou avaliar as concepções prévias dos estudantes, criamos um parâmetro ou referencial para analisarmos quantitativamente como qualitativamente os conceitos prévios que os estudantes tinham sobre o tema a ser estudado, de modo a gerarmos uma sequência didática que produzisse uma aprendizagem significativa. Com a sua reaplicação no final da sequência didática teremos um meio de avaliar se o emprego desta sequência didática geraria uma mudança conceptual nos estudantes de modo que uma grande parcela deixaria de usar concepções espontâneas e passassem a usar concepções científicas nas suas explicações para os fenômenos da natureza. Note-se que complementando essa avaliação inserimos questões do tipo vestibular em nosso questionário, de modo a avaliarmos primeiramente o nível médio de aprendizagem tradicional que os alunos tinham e em segundo lugar a melhora da performance destes após a aplicação do projeto.

\section{Resultados e discussões}

Apresentaremos aqui um resumo dos resultados quantitativos e qualitativos resultante da aplicação da sequência didática nas duas escolas ${ }^{3}$. Aproximadamente 80 alunos participaram das nossas atividades, somando os alunos das duas escolas. Apesar do número de alunos participantes não ser muito expressivo em relação às pesquisas realizadas em outras pesquisas ${ }^{4}$, os resultados estatísticos são concludentes. Corroborando este fato apresentamos um resumo dos resultados qualitativos.

Todos os testes, questionários e depoimentos foram feitos sem identificação dos nomes dos discentes, tendo apenas que definir o sexo e a idade. Por isso, não podemos afirmar se foram os mesmos alunos que participaram de todas as atividades no período da coleta. As análises dos dados coletados serão separadas por escolas, para que assim, se possa fazer uma comparação do rendimento dos alunos. Note-se que na escola A nossa sequência foi interrompida por aproximadamente cinco semanas devido à greve e ao período de avaliações dos alunos.

\footnotetext{
3 Maiores detalhes ver Souza (2015).

${ }^{4}$ Em comparação com pesquisas típicas realizadas por exemplo nos E.U.A.
} 
Após o campeonato de aviões de Papel aplicou-se um questionário do tipo Pós-Teste. Objetivou-se primeiramente em analisar a aprendizagem significativa dos alunos em relação ao conteúdo abordado no material de apoio, verificar se os mesmos passaram em média a usar mais explicações aos fenômenos Físicos baseadas em concepções científicas do que em alternativas e a consolidação desse método. Foi observado que mesmo ocorrendo na escola A uma quebra na aplicação da sequência didática devido a uma greve obtivemos resultados extremamente positivos. A média geral nas duas escolas ocorreu um aumento de mais de $84 \%$. Ver Fig. 6.

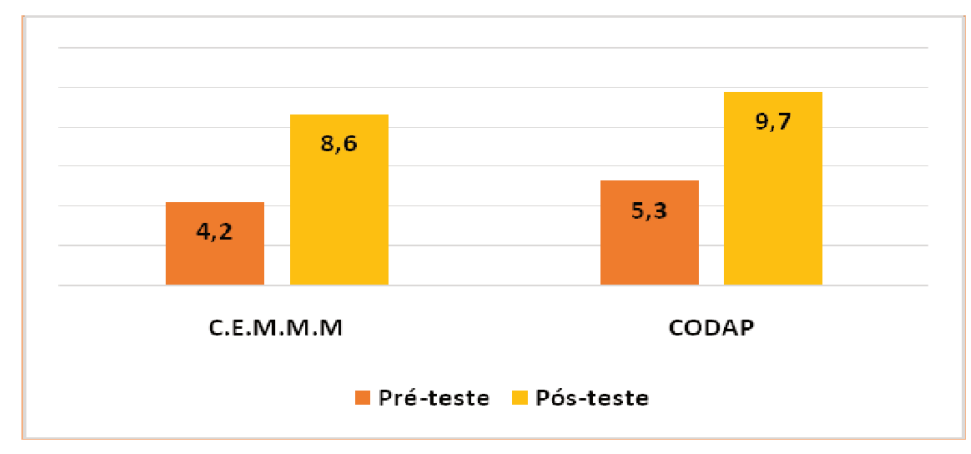

Fig. 6-Gráfico da média dos resultados comparativos do pré-teste e pós-teste das duas escolas.

A seguir apresentaremos uma análise geral comparada das questões em forma de gráficos, onde o lado esquerdo encontram-se os resultados da escola A e do lado direito os valores da B. Começaremos analisando as possíveis mudanças nas concepções alternativas dos alunos seguidas de aprendizagem significativas.

Quanto às questões do tipo concepções alternativas observou-se um aumento, em geral, de mais de $70 \%$ no uso de concepções científicas em contraposição às alternativas. Em alguns itens essa melhora foi de $200 \%$ até $440 \%$. Como exemplo de questão do tipo concepções alternativas para ser analisada aqui, escolhemos a terceira questão de nosso questionário, tirada do artigo Ure at all (1994), pois esta tem o objetivo de demonstrar o domínio do conceito de conservação da quantidade de movimento. Para as demais questões, ver Santos (2015).

03 - Pedro e Paulo estão em pé sobre dois carrinhos que podem se movimentar com atritos despreziveis sobre um plano horizontal no laboratorio. No inicio, os dois estão em repouso, com Pedro segurando uma bola pesada.

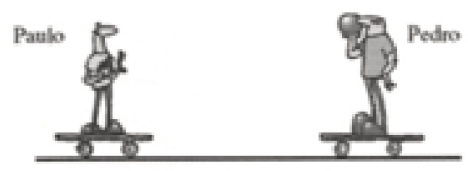


Pedro lança a bola para Paulo, que a apanha e lança de novo para Pedro, o qual por sua vez a apanha, conservando-a com ela. Qual dos seguintes esquemas representa as quantidades de movimento de Pedro e Paulo no final da sequência?

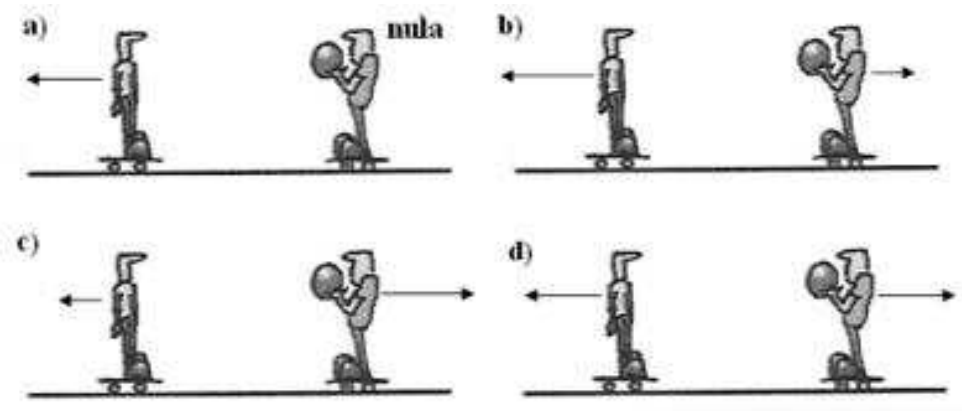

O aluno deveria ter atenção para o início da questão onde afirmava que o atrito era desprezível, com isso a quantidade de movimento se conserva. Logo, a opção correta é a "D", e se observa que menos de $36 \%$ dos alunos acertam no pré-teste (Fig. 6). O aluno que optou pela alternativa "C", de acordo com Ure at al. (1994) intuitivamente confundiu quantidade de movimento com força.

Analisando o gráfico comparativo de acertos da questão 3 (Fig. 7) é fácil perceber que aconteceu uma mudança quanto ao uso de concepções alternativas para científica com relação a este item. Os valores da alternativa " $D$ " que é a correta, passaram de no máximo $36 \%$ no primeiro momento para no mínimo $62 \%$ no pós-teste, resultando num aumento aproximado de $100 \%$. As demais alternativas obtiveram redução significativa nos valores no pós-teste.

Analisando o lado direito da figura para a escola B, percebemos duas situações as quais merecem nosso destaque. O número de estudantes que optaram pela alternativa correta dobrou, mas a alternativa "B" passou de $2 \%$ no pré-teste para $23 \%$ no pós-teste, ou seja, apesar da porcentagem na alternativa correta ter sofrido um aumento, muitos alunos ainda permanecem com a concepção alternativa que o bonequinho mais "forte" apresenta a maior força, confundindo força com quantidade de movimento. Em geral, observou-se que em média $25 \%$ dos estudantes ainda continuavam a usar concepções prévias.

Em contraposição às questões do tipo concepções prévias, aplicamos algumas questões do "tipo vestibular". Como exemplo, a questão 06 é tipicamente uma questão de vestibular e envolve conceitos de energia potencial e cinética. Vemos na Fig. 8 que se teve 59\% de acertos no pré-teste para a escola A e 79\% para a escola B. Observando ainda essa figura vemos através dos resultados do pós-teste que tivemos uma melhora no desempenho dos estudantes neste tipo de questão após a aplicação da sequência didática. Comparando com os resultados das questões do tipo concepções prévias percebemos que $65 \%$ no total dos alunos tiveram êxito na questão 6, enquanto que em média somente $30 \%$ tinham êxito nas questões tipo concepções prévias. Ou seja, os alunos estão mais acostumados a lidarem com questões mais diretas. 


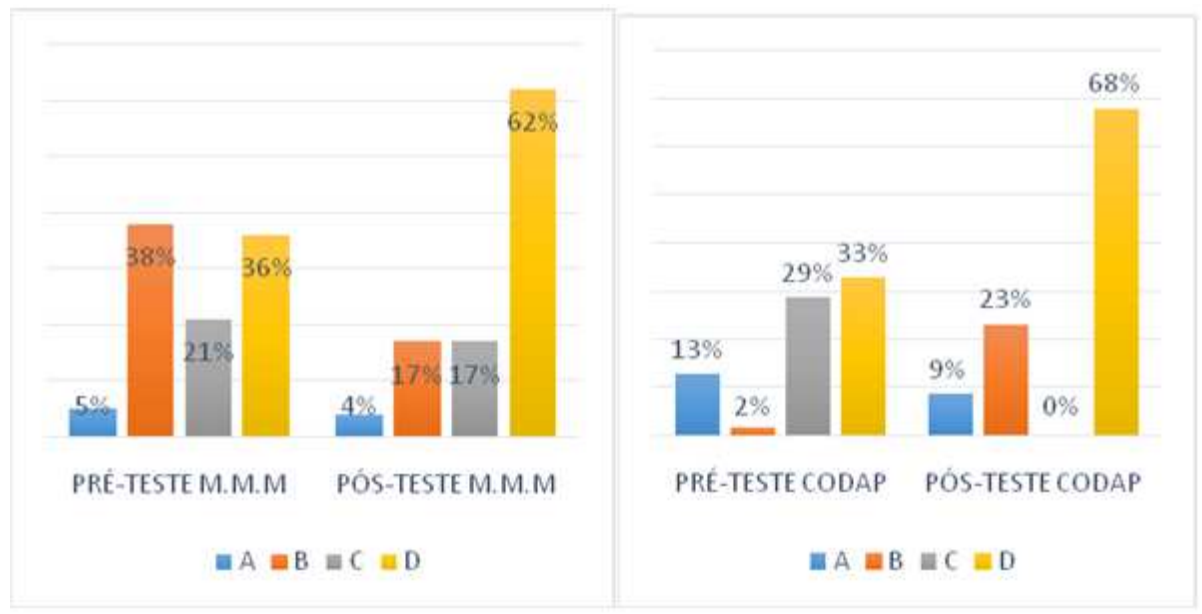

Fig. 7 - Gráfico comparativo dos resultados da questão 03 do pré-teste e pós-teste duas escolas.

06- A figura abaixo mostra o movimento de uma pedra que foi lançada verticalmente para cima, a partir do solo.

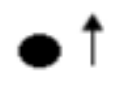

A medida que a pedra sobe livremente no campo gravitacionall terrestre, aumenta:
a) O módulo da velocidade da pedra.
b) O módulo da aceleração da pedra.
c) A energia cinética da pedra.
d) A energia potencial gravitacional da pedra.

\section{Desempenho dos alunos no jogo dos sete erros e caça palavras}

Um resultado muito importante de nosso trabalho foi a aplicação do jogo dos sete erros (Fig. 5) e o caça palavras (Anexo 1). Essa atividade lúdica tinha como objetivo avaliar os alunos referente à aprendizagem significativa e foi resolvida individualmente e em média os estudantes responderam em 40 minutos. Ao contrário dos exames (provas) convencionais, os alunos demonstraram entusiasmo em participar do jogo. Durante esta ação os discentes criaram entre si uma espécie de competição para quem encontrassem mais palavras no jogo "Caça Palavras" e acertassem os erros.

Percebemos que a porcentagem de acertos no jogo dos sete erros variou entre dois a sete erros. Percebemos que $65 \%$ dos alunos conseguiram identificar mais de cinco erros, e ape- 
nas $3 \%$ encontraram os sete erros na imagem do avião. Isso é devido que colocamos (em linguagem popular) uma "pegadinha", isto é, colocamos os vetores Força Peso nas asas do avião de modo a verificarmos se estes tinham aprendido o conceito de centro de gravidade.
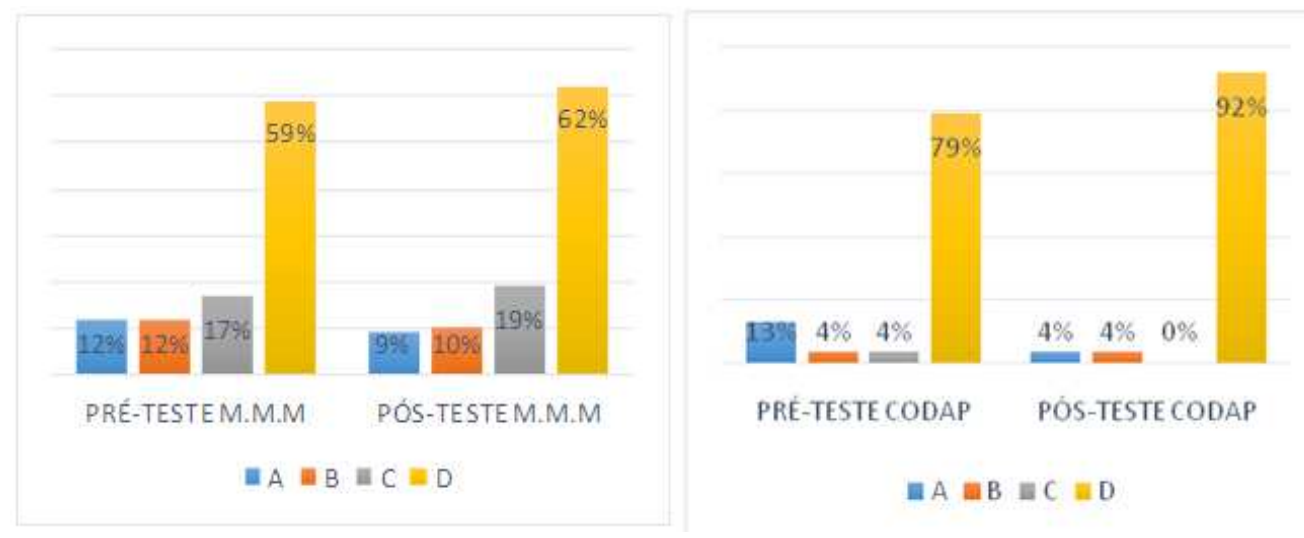

Fig. 8 - Gráfico comparativo dos resultados da questão 06 do pré-teste e pós-teste duas escolas.

Quanto ao jogo caça palavras $23 \%$ dos participantes encontraram todas as palavras corretas, $49 \%$ encontraram pelo menos 10 palavras, $63 \%$ encontraram pelo menos nove palavras e $77 \%$ encontraram pelo menos 8 palavras. Os resultados com maiores porcentagens nos indica que os acertos sofreram variação entre oito e dez palavras encontradas corretamente. $\mathrm{O}$ interessante é que nenhum deles reclamou de ser avaliado e todos estavam interessados em quantas palavras tinham no jogo. Alguns acharam até palavras que não tínhamos projetado como "air".

\section{Considerações finais}

A utilização de um campeonato de avião de papel como atividade motivadora para introduzir o conteúdo de Hidrodinâmica e revisar conceitos de Mecânica que influenciam na física do voo de um avião, fez com que despertassem nos alunos interesse e o gosto pela Física como também contribuiu com uma maior aprendizagem.

Comparando os valores dos escores encontrados com aplicação do pré-teste e pós-teste sobre concepções alternativas percebemos que a sequência didática contribuiu para uma evolução significativa do uso de concepções científicas por parte dos discentes. Logo, podemos concluir que em média ocorreu uma mudança conceitual e aprendizagem significativa por parte dos estudantes. Ou seja, o conhecimento intuitivo foi confrontado aos conceitos científicos. Comparando as porcentagens de acerto das questões do tipo vestibular com as do tipo concepções prévias, percebe-se que apesar dos estudantes estarem preparados para responder as primeiras, eles não estão para as segundas. Ou seja, o ensino tradicional, mesmo em escolas padrão, não produz aprendizagem significativa. 
Durante as atividades no laboratório de informática com o software Modellus os alunos demonstraram interesse e surpresa. As simulações ajudaram aos alunos a compreenderem os conteúdos abordados, assim como visualizar melhor o problema físico modelado. Comentários como: "podendo visualizar quase que diretamente o que é visto em aula, nós alunos, nos interessarmos mais pelo assunto", "foi divertido", "legal", "adorei aprender brincando", fizeram parte das opiniões dos alunos. Pode-se ver aqui, uma demonstração da aplicação das ideias sobre modelos mentais de Johnson-Laird.

Constatamos que a utilização de jogos como forma avaliativa contribui com o sucesso da sequência didática. Os discentes responderam os jogos, se divertiram, colocaram em prática o que tinham aprendido na sequência didática.

Conclui-se que o uso de uma sequência didática contendo jogos, atividades experimentais e o uso de simulação com um software para o ensino de Hidrodinâmica, podem ser bons recursos instrucionais para o Ensino de Física. Podendo colaborar como alternativa inovadora as aulas tradicionais.

Cabe notar que Mendes (1999) obteve resultados inconclusos em pesquisa anterior utilizando uma sequência didática construída a partir do Software Modellus e o experimento de baixo custo lançamento de foguete. A turma que teve melhor desempenho foi justamente o grupo controle.

Esta sequência didática demonstrou que há várias formas de se tornar o ensino de conteúdos de Física mais atraente. Como o exemplo usado aqui, temos que o tema de divulgação científica - a física envolvida em um voo de um avião - com a realização de oficinas de aviões de papel, conjuntamente com o uso de jogos no ambiente escolar e com a utilização de uma simulação computacional no estudo da Hidrodinâmica pode tornar o aprendizado deste tema da Física prazeroso e significativo (AUSUBEL, 1989).

\section{Referências Bibliográficas}

ANDALORO, G.; DONZELLI, V.; SPERANDEO, R. M. Modelling in physics teaching: the role of computer simulation. International Journal of Science Education, v. 13, n. 3, 1991.

ARNAUDIN, M. W.; MINTZES, J. J. "Students' alternative conceptions of the human circulatory system: a cross-age study.” Science Education, v.69, n. 5, p. 721-733, 1985.

AUSUBEL, D. Aquisição e retenção de conhecimentos: uma perspectiva cognitiva. 1. ed. Lisboa: Plátano Editora, 2003.

AUSUBEL, D. P. et al. Psicologia educacional. Rio de Janeiro: Internamericana, 1980. 216p.

AUSUBEL, D. P. Adquisición y retención del conocimiento: una perspectiva cognitiva. Barcelona: Paidós, 2002. 328pn 
BELL, A. BREKKE, G.; SWAN, M. "Misconceptions, Conflict and Discussion in the Teaching of Graphical Interpretation.” In: International Seminar on Misconception and Educational Strategies in Science and Mathematics, $2^{\text {nd }}, 1987$, Ithaca. Anais... Ithaca, NY: Cornell University Press, 1987, v. 1. p. 46-58.

CAREY, S. Cognitive Science and Science Education. American Psychologisty, 1987.

CAVALCANTI, E. L. D.; SOARES, M. H. F. B. O uso do jogo de roles (roleplaying game) como estratégia de discussão e avaliação do conhecimento químico. Revista Electrónica de Enseñanza de las Ciencias, v. 8, n. 1, 2009.

CIENCIAMÃO. Recursos para Educação em Ciências, 2015. Disponível em: $<$ http://www.cienciamao.usp.br/tudo/exibir.php?midia=lcn\&cod=_aforcadoar-principiodaac>. Acesso em: 12 nov. 2015.

CLEMENT, J. Students Preconceptions in Introductory Mechanics. American Journal of Physics, v. 50, n. 1, p. 66-71, 1982.

DELATORRE, R. G. (2013); M. P. BECKER et al. A física no voo de aviões de papel: uma abordagem prática e experimental para o ensino de física e de conceitos aerodinâmicos. In: CONGRESSO BRASILEIRO EM ENGENHARIA, XLI, 2013. Anais... Disponível em: $<$ http://www.fadep.br/engenharia-eletrica/congresso/pdf/117227_1.pdf>. Acesso em: 12 nov. 2015.

DRIVER, R.; EASLEY, J. Pupils and paradigms: A review of literature related to concept development in adolescent science students. Studies in Science Education, Leeds, v. 5, p. 61-84, 1978.

DUIT, R. On the role of analogies and metaphors in learning science. Science Education, v. 75, p. 649-672, 1991.

EDUC@r. Centro de divulgação científica e cultural, 2015. Disponível em: <http://www.cdcc.usp.br/>. Acesso em: 12 nov. 2015.

ENEM. Exame Nacional do Ensino Médio, 2015. Disponível em: <http://portal.inep.gov.br/ web/enem/sobre-o-enem>. Acesso em: 12 nov. 2015.

FREIRE, P. Pedagogia do Oprimido. 43. ed. Rio de Janeiro: Paz e Terra, 2005.

GALAGOVSKY, L. Y.; ADÚRIZ-BRAVO, A. Modelos y Analogías en la Enseñanza de las Ciencias Naturales. El Concepto de Modelo Didáctico Analógico. Enseñanza De Las Ciencias, v. 19, n. 2, p. 231-242, 2001.

GARCIA, A. F. Física con ordenador, 2015. Disponível em: <http://www.sc.ehu.es/ sbweb/ fisica/. Acesso em: 12 nov. 2015. 
GEF. Grupo de ensino de Física. Disponível em: <http://coral.ufsm.br/gef/>. Acesso em: 12 nov. 2015.

GILBERT, J. K. Models And Modelling In Science Education. Ed. Spring-Verlag. Herts: Association for Science Education, 1993.

GILBERT, J. K.; SWIFT, D. J. Towards a lakatosian analysis of the piagetian and alternative conceptions research programs. Science Education, v. 69, Issue 5, p. 681-696, October 1985.

GILBERT, S.W. Model Building and a Definition Of Science. Journal of Research in Science Teaching, v. 28, 73-79, 1991.

GLYNN, S. M. (1991). Explaining science concepts: A teaching-with-analogies model. In: GLYNN, S.; YEANY, R.; BRITTON, B. (Eds.). The psychology of learning science. Hillsdale, NJ: Erlbaum. p. 219-240

GRECA, I. M.; MOREIRA, M. A. Mental, physical, and mathematical models in the teaching and learning of physics. Science Education, v. 86, p. 106-121, 2002.

GRECA, I. M.; MOREIRA, M. A. Un estudio piloto sobre representaciones mentales, imágenes, proposiciones y modelos mentales respecto al concepto de campo electromagnético en alunos de física general, estudiantes de postgrado y físicos profesionales. Investigações em Ensino de Ciências, Porto Alegre, v. 1, n. 1, p. 95-108, abr. 1996.

GUIMARÃES, C. C. Experimentação no ensino de química: caminhos e descaminhos rumo à aprendizagem significativa. Química Nova na Escola, v. 31, n. 3, 198-202, 2009.

HALLOUN, I. Schematic modeling for meaningful learning of physics. Journal of Research in Science Teaching, v. 33, p. 1019-1041, 1996.

HAMPSON, P. J.; MORRIS, P. E. Understanding cognition. Oxford, UK: Blackwell, 1996.

HARRISON. How do Teachers and Textbook Writers Model Scientific Ideas for Students? Research in Science Education, v. 31, p. 401-435, 2001.

HOLTON, G. The project physics course, then and now. Science \& Education, v. 12, p. 779786, 2003.

JOHNSON-LAIRD, P. N. Modelos mentales en ciencia cognitiva. In: NORMAN, D. A. (Ed.) Perspectivas de la ciencia cognitiva. Barcelona: Ediciones Paidós, 1997. p. 179-231.

IZQUIERDO, M.; SANMARTÍ, N.; ESPINET, M. Fundamentación y diseño de las prácticas escolares de ciencias experimentales. Enseñanza de las Ciencias, v. 17, n. 1, p. 45-59, 1999.

KINNEAR, J.; MARTIN, M. Nature of biology: Book one. Milton, Queensland: The Jacaranda Press, 1992. 
KOPONEN, I. T. Modelling in physics teaching: the role of computer simulation. International Journal of Science Education, v. 13, Issue 3, 2007.

LAKATOS, E. M. Metodologia Do Trabalho Científico. 7. ed. São Paulo: Atlas, 2011.

LEITE, F. T. Metodologia Científica. 3. ed. São Paulo: Editora Ideias \& letras, 2008.

LEITE, L. S. F. Concepções Alternativas em Mecânica. Um contributo para a compreensão do seu conteúdo e persistência. 1993. Tese (Doutoramento) - Universidade do Minho, Portugal. Disponível em: <http://repositorium.sdum.uminho.pt /handle/1822/54>. Acesso em: 01 jun. 2015

LUCKESI, C. C. Avaliação da aprendizagem na escola e a questão das representações sociais. Eccos Revista Científica, v. 4, n. 2, p. 79-88, 2002.

MENDES, J. F. O uso do software modellus na integração entre conhecimentos teóricos e atividades experimentais de tópicos de mecânica sob a perspectiva da aprendizagem significativa. 2009. Dissertação (Mestrado) - Universidade de Brasília.

MESTRE, J.; TOUGER, J. Cognitive Research - What's in It for Physics Teachers?, 1988.

MOREIRA, M. A Modelos Mentais. Investigações em Ensino de Ciências, v. 1, n. 3, p.193$232,1996$.

MOREIRA, M. A Teorias de aprendizagem. São Paulo: Editora Pedagógica Universitária, 1999. 101p.

MOREIRA, M. A; LEVANDOWSKI, C. E. Diferente abordagens ao ensino de laboratório. Porto Alegre: Editora da Universidade Federal do Rio Grande do Sul, 1983.

NESSERSSIAN, N. J. How do Scientist Think? Capturing the Dynamics of Conceptual Change in Science. In: Cognitive Models of Science. Minneapolis: University of Minnesota Press. p. 3-44.

NUFFIELD. Nuffield Science Teaching Project. Disponível em: <http://www.nuffieldfoundation.org/nuffield-science-teaching-project>. Acesso em: 01 jun. 2015.

OEI. Organización de Estados Iberoamericanos. Disponível em: <http://www.oei.es/divulgacion cientifica/reportajes_444.htm>. Acesso em: 01 jun. 2015.

OGBORN, J.; KRESS, G., MARTINS, I.; MCGILLICUDDY, K. Explaining science in the classroom. Buckingham, UK: Open University Press, 1996.

PEF. Projeto de Ensino de Física, Guia do Professor. Rio de Janeiro, Fename, 1980.

PEREIRA, A. M. R. Avião de papel. Projeto de peças. Disponível em:

$<$ http://www.ebah.com.br/ content/ABAAAfGpkAG/aviao-papel>. Acesso em: 01 jun. 2015. 
PHET. Interactive Simulations For Science And Math. Disponível em: <https://phet.colorado.edu/pt_BR/>. Acesso em: 01 jun. 2015.

PIBID. Programa Institucional de Bolsa de Iniciação à Docência. Disponível em: <http://www.capes.gov.br/educacao-basica/capespibid>. Acesso em: 01 jun. 2015.

PNLD (2015). Programa Nacional do Livro Didático. Disponível em: <http://www.fnde.gov.br/programas/livro-didatico/guias-do-pnld/item/5940-guia-pnld-2015>. Acesso em: 01 jun. 2015.

PNLEM (2015). Programa Nacional do Livro Didático para o Ensino Médio. Disponível em: $\leq$ http://portal.mec.gov.br/index.php?Itemid=582\&id=12371\&option=com_content\&view $=$ article $>$. Acesso em: 01 jun. 2015.

PSSC. Physical Science Study Committee. Disponível em: <http://libraries.mit.edu/ archives/exhibits/pssc/>. Acesso em: 01 jun. 2015.

MORTINER, E. F. Construtivismo, mudança conceitual e ensino de ciências: Para onde vamos? Investigações em Ensino de Ciências, v. 1, n. 1, p. 20-39, 1996.

RICHARDSON, R. J. Pesquisa Social: método e técnicas. 3. ed. São Paulo: Atlas, 1979.

RIVED. Rede interativa virtual de educação. Disponível em: <http://rived.mec.gov.br/>. Acesso em: 01 jun. 2015.

RODRIGUES, S. L.; NASCIMENTO, R. C. G. Avaliação escolar: cenas de um processo multifacetado, 2014. Disponível em: <http://unicruz.edu.br/mercosul/pagina/anais/ 2014/DIREITO\%20A\%20EDUCACAO/ARTIGO/ARTIGO\%20-\%20AVALIACAO\%20ESCOLAR. PDF>. Acesso em: 01 jun. 2015.

SAAD, F. D. Demonstrações em Ciências. 1. ed. São Paulo: Editora Livraria da Física, 2005. $96 \mathrm{p}$.

SADLER, P. M. (1992). The Initial Knowledge State of High School Astronomy Students. A Dissertation Presented to the Faculty of the Graduate School of Education of Harvard University in Partial Fulfillment of the Requirements for the Degree of Doctor of Education.

SALEM, S. (2012). Perfil, evolução e perspectiva da Pesquisa em ensino de Física no Brasil. 2012. Tese (Doutorado) - Programa de Ensino Interunidades, USP. Disponível em: <http://www.teses.usp.br/teses/disponíveis/81/81131/tde-13082012-110821/pt-br.php>. Acesso em: 13 jun. 2015.

SILVA; A. Jogos e avaliação no processo ensino-aprendizagem: uma relação possível. REnCiMa, v. 2, n. 1, p. 1-8, jan/jun 2011. 
SILVEIRA, R. S.; BARONE, D. A. C. Jogos Educativos computadorizados utilizando a abordagem de algoritmos genéticos. Universidade Federal do Rio Grande do Sul, Instituto de Informática, Curso de Pós-Graduação em Ciências da Computação, 1998.

SOUZA, E. J.; MELLO, L. A. Desafios no uso de softwares de ensino no aperfeiçoamento da prática docente. In: ENCONTRO DE FORMAÇÃO DE PROFESSORES, 6, 2013, Aracaju. Anais... Aracaju: Universidade Tiradentes, 2013. Disponível em: <http://ww3.unit.br/6enfope/anais/>. Acesso em: 12 nov. 2015.

SOUZA, E. J. O uso de jogos e simulação computacional como instrumento de aprendizagem: campeonato de aviões de papel e o ensino de Hidrodinâmica. 2014. Dissertação (Mestrado) - UFS.

STUDART, N.; S.R. DAHMEN. A física do voo na sala de aula. Física na Escola, v. 7, n. 2, 2006.

TEODORO, V. D. Modellus: experiments with mathematical models. Disponivel em: $<$ http://phoenix. sce. fct. unl. pt/modellus/>.

VEIT, E. A.; ARAUJO, I. S. Modelagem computacional no Ensino de Física. Revista do Centro de Educação da Universidade Federal de Alagoas, CEDU, 2005.

VEIT, E. A.; TEODORO, V. T. Modelagem no ensino/aprendizagem de Física e os novos Parâmetros Curriculares Nacionais para o Ensino Médio. Revista Brasileira de Ensino de Física, v. 24, n. 2, São Paulo, Jun. 2002.

VILLANI, A.; CABRAL, T. C. B. Mudança Conceitual, Subjetividade E Psicanálise. Investigações em Ensino de Ciências, v. 2, n. 1, p.43-61, 1997.

WELLS, M.; HESTENES, D.; SWACKHAMER, G. A modelling method for high school physics instruction. American Journal of Physics, v. 63, p. 606-619, 1995.

ZANON, D. A. V.; GUERREIRO, M. A. da S.; OLIVEIRA, E R. C. de Jogo didático Ludo Químico para o ensino de nomenclatura dos compostos orgânicos: projeto, produção, aplicação e avaliação. Ciências \& Cognição, v. 13, n. 1, 2008.

ZOOK, K. B. Effect of analogical processes on learning and misrepresentation. Educational Psychology Review, v. 3, n. 1, p. 41-72, 1991.

\section{Anexo 1 - Cruzadinha da Física}




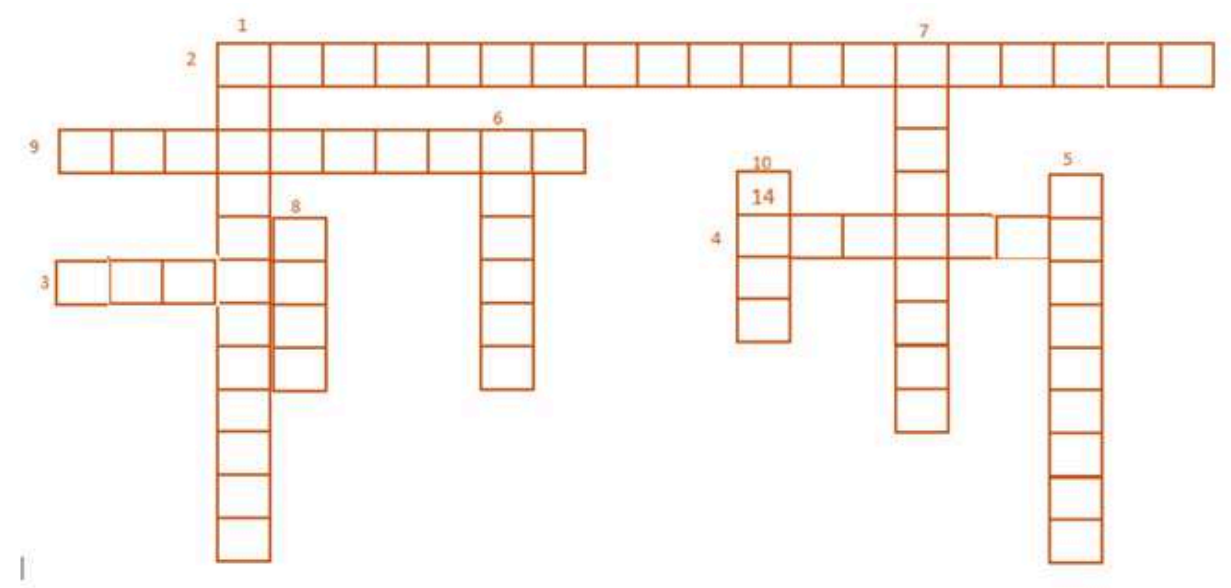

1- Parte da Física que estuda a força do ar sobre os corpos em movimento.

2- Nome do inventor do avião de acordo com os critérios estabelecidos pela Federação Aeronáutica Internacional.

3- Cidade do primeiro voo assistido por juízes avaliadores.

4- Avião que formado por duas asas paralelas ligadas por uma superficie de sustentação.

5- Avião de um único motor.

6- O mesmo que força de arrasto/ resistência do ar é força de...

7- Fase do voo em que a aeronave deixa o solo.

8- Parte responsável pela sustentação aerodinâmica.

9- O mesmo que pousar em terra.

10- Nome do primeiro avião.

\section{Gabarito}

\begin{tabular}{|c|c|c|c|c|c|c|c|c|c|c|c|c|c|c|c|c|c|c|c|c|c|}
\hline & & & A & $\mathrm{L}$ & B & $\mathrm{E}$ & $\mathrm{R}$ & $\mathrm{T}$ & 0 & $\mathrm{~s}$ & A & $\mathrm{N}$ & $\mathrm{T}$ & 0 & $S$ & D & $\mathrm{U}$ & $\mathrm{M}$ & 0 & $\mathrm{~N}$ & $\mathrm{~T}$ \\
\hline & & & $E$ & & & & & & & & & & & & & $E$ & & & & & \\
\hline \multirow[t]{3}{*}{ A } & $\mathrm{T}$ & $\mathrm{E}$ & R & $R$ & 1 & $z$ & A & $\begin{array}{ll} \\
\end{array}$ & & & & & & & & C & & & & & \\
\hline & & & 0 & & & & $\mathrm{~T}$ & & & & & & 1 & & & 0 & & & $\mathrm{M}$ & & \\
\hline & & & D & A & & & R & & & & & & B & I & $P$ & L & A & $\mathrm{N}$ & 0 & & \\
\hline \multirow[t]{7}{*}{$P$} & A & $R$ & 1 & $S$ & & & 1 & & & & & & 1 & & & A & & & $\mathrm{N}$ & & \\
\hline & & & $\mathrm{N}$ & A & & & $\mathrm{T}$ & & & & & & $S$ & & & G & & & 0 & & \\
\hline & & & A & $S$ & & & 0 & & & & & & & & & $E$ & & & $\mathrm{M}$ & & \\
\hline & & & $M$ & & & & & & & & & & & & & $M$ & & & 0 & & \\
\hline & & & 1 & & & & & & & & & & & & & & & & $\mathrm{~T}$ & & \\
\hline & & & $C$ & & & & & & & & & & & & & & & & 0 & & \\
\hline & & & A & & & & & & & & & & & & & & & & $\mathrm{R}$ & & \\
\hline
\end{tabular}

